\title{
Enlightenment of American E-learning to the Teaching of Kindergarten Curriculum
}

\author{
Pei Zhang \\ Shanghai Normal University College of Education, Jiangsu 215000, China
}

Keywords: American curriculum; E-education; Kindergarten

Abstract: E-education and e-learning have penetrated into all aspects of children's learning and life under the impetus of global electronic technology. This paper takes American public kindergartens and primary schools as examples to introduce the application of e-education teaching in basic education in the United States. How does the curriculum in kindergarten education in China combine with e-learning technology?

\section{Application of American Educational Software in Schools: A Case Study of Massachusetts Public Primary Schools}

In 2018, the author visited several public elementary schools in Massachusetts, USA. From kindergartens (kindergarten equivalent to preschool classes in China) to elementary school classes, e-education is everywhere in every classroom. According to the author's observation of the school where he visited, the following are the main points of the use of electronic education in the United States in primary schools:

\subsection{Types and contents of e-education}

The electronic education technology of public schools in the United States mainly includes two types of display software and operation software. The display of the same city uses the use of multimedia equipment as a carrier, using information technology for educational display and viewing. These equipment picture photo projections, similar to the recorder's voice story player, electronic books, iPad, computer and so on. The operation class requires students to interact with electronic devices, usually using educational software as a carrier to perform real-time interactive operations between human and computer on a computer. Due to the diversification of electronic software design, e-education can be displayed in teaching. Students can solve problems and solve problems and can be divided into individual answers and team answers, which are benefited from the design and setting of e-education software.

\subsection{The scope of application of electronic education radiation}

E-education has a wide range of applications in primary schools in the United States, mainly in the use of e-education technology in the grade range from kindergarten to elementary school 1-6. In addition, each student basically has electronic devices that can be operated independently. The 
primary school is more than 3 years old. The students have a laptop and can be used in the classroom without going to a separate computer room and computer room. There are a variety of electronic equipment in the lower grades of elementary school. Each classroom is equipped with 2-3 kinds of electronic education equipment. Although the number cannot guarantee the whole class at the same time, in terms of learning methods, students use electronic equipment in groups, and everyone has You can use an electronic device by yourself.

\subsection{Many subjects in e-education}

American primary schools mainly teach reading, mathematics, science, society, music, and art. For example, in the low grades, reading classes use more electronic devices, mainly for students to listen to stories on the radio with books and listen to the dynamic reading materials of the iPad. In the math class, students are used to answer questions or watch problem solving.

\subsection{The proportion of e-education teaching time is long}

During the visit, because the subjects and students are different in age, the e-education teaching time is different and the purpose is different. In general, e-education can be applied to all aspects of teaching, so the time ratio of students using electronic equipment is also very high. Big. The older children are in elementary school for 4 or 5 years. Basically, the whole science class is completed on the computer. The teaching content of the class is to complete the learning and consolidation of the rocket knowledge through the group answering contest.

\subsection{Forms of students participating in e-education}

The teaching of e-education is different from teaching and teaching. There are two forms of e-education for students. One is personal operation and the other is collective teaching. However, it is basically based on individual participation, and the application of e-education in group teaching is generally less to show the content of education. Therefore, students are mostly self-directed, that is, more self-exploration and operation.

The electronic information education in the United States started earlier. In 1966, it began to pay attention to the application of computers to teaching, and to study computer-aided education (CAI) ${ }^{[1]}$. In the 1990s, information technology and electronic technology developed in an all-round way. The US Department of Education released it in 1996. The first national education technology plan "Helping American students prepare for the 21st century: Meeting the challenges of technical literacy", from 2010 to 2010, the US Department of Education has released four national educational technology programs.

\section{The development and application of China's electronic education technology}

The application of e-education in China also has its own characteristics, which can be elaborated from two aspects, one is ordinary school education, and the other is market-oriented education. From the perspective of school education, the use of e-education technology in China is still at the stage of exhibition. On the one hand, due to the large number of Chinese students, it is difficult for electronic equipment to become popular in schools. On the other hand, China also lacks of the high quality education softwares. The design of electronic education teaching software that matches the textbook has a low overall development level of the educational software market. These two aspects have hindered the development and innovation of China's e-education technology in the school. Therefore, the application form of e-education in China is mostly the use of electronic information 
technology to presentation. It does not touch on the changes and changes in the education and teaching model. Therefore, it has not had any influential changes in the teaching effect.

Different from school education, from the perspective of education in the market, the electronic education equipment, software and application of extracurricular tutoring are extremely hot, and there are endless streams of language teaching. The most popular English language is the interactive mode of operation. The mobile phone can be used to learn anytime and anywhere, such as providing film broadcast news materials for materials, game learning, real-life interactive one-on-one forms, online classrooms, classroom live broadcasts, etc. The design process is also a fun language learning, stimulating students' desire to learn. The reason for this phenomenon is related to the income of family economy and the popularity of electronic equipment in China, and it is also related to the huge demand for education in the market. On the one hand, parents need more education in their companionship and ability to educate their children. On the other hand, from the economic point of view, the price of educational software is also very advantageous compared with the remedial classes under the class, and it also eliminates the problem of parents picking up children. Comprehensively, the huge opportunities in the market have also stimulated relevant Research institutions, research and development and investment of enterprises. However, due to the backward development of evaluation institutions of Chinese software, the evaluation standards and evaluation systems are still not perfect. Although there are many electronic educational equipment's and software on the market, there are also a large number of design problems. For example, in China's early childhood education software, there is no system and normative evaluation system, and there are few relevant evaluation institutions and research groups, which leads to problems such as low level, high repetition rate and waste of resources in the development of early childhood education software ${ }^{[2]}$. The quality and suitability of the software cannot be regulated and evaluated.

\section{E-education and how to integrate with the kindergarten curriculum in China}

\subsection{The role and influence of e-education and e-learning on young students}

The essence of e-education and e-learning is learning and cognitive tools. The application of electronic information technology in education is to improve the efficiency of teaching and learning. In Singapore, the world's leading computer network readiness index, its education minister mentioned that the ultimate goal of Singapore education is not to use information technology in teaching, but to use information technology to change teachers and school culture, promote and Support students' thinking and independent learning ${ }^{[3]}$.

The learning effect of e-education has been demonstrated for a long time. As a teaching aid, e-education and e-learning are more effective in teaching and training than traditional methods in certain disciplines and training. Especially in the younger grades, e-learning is more effective than traditional education in attracting children's attention and learning interest. Xiao Junwei and Yang Huijie's experiment on the practice of learning software based on the attention of children's attention to stability found that learning software has certain gameplay. It provides the possibility of independent operation without the help of parents, which can attract children's attention and cultivate their initiative. Learning ability ${ }^{[4]}$.

\subsection{E-education and integration with kindergarten curriculum in China}

There is no doubt that e-learning and e-learning have entered the learning and life of children. Information technology provides children with self-expression, understanding of the world, games and communication, exploring the environment, and ways and tools to solve problems. How to use strengths and avoid weaknesses, rational and effective use of electronic technology has put forward 
new requirements and challenges for early education. According to Guo Liping's "Information Technology and Early Education" point of view.

First of all, there are three modes for the integration of electronic information technology and curriculum: First, the standard-based curriculum model, such as how to learn information retrieval in the information technology class. Second, the auxiliary curriculum model uses information technology to create, social, cultural, and natural scenarios in educational activities; create problem scenarios and create virtual laboratories. Third, the research-based curriculum model: through social surveys, identify topics, group cooperation and other links to complete the course. Children use information technology as a learning tool and means to obtain.

Secondly, there are two main ways in which electronic technology can be realized in curriculum integration. One is from curriculum to software, that is, selecting appropriate software to enrich curriculum content, educational activities and concepts, and the other is from software to curriculum, that is, utilization. Regular activity materials and teaching paradigms enrich and develop appropriate software content. But these two methods are not completely separate, complement each other.

The above electronic education technology can be combined with the kindergarten curriculum in the following three ways.

Firstly, the combination of thematic activities. Thematic activities are different types of activities that circulate around a topic, helping the child's general knowledge and skills to migrate in different empirical situations. For example, through educational software, young children can more intuitively observe that animals, plants and the entire ecological environment change with the seasons. Young children may have different interests and problems after learning. Teachers can produce different exploration themes from different perspectives according to children's different interests, such as the study of the characteristics of trees, including planting observation experiments; and the creatures around us. The theme is to find the animals and plants in the surrounding environment. This series of activities from electronic software content has become a meaningful topic of inquiry for children. Educational simulation software provides an environment for children to experience and observe, non-hazardous, inexpensive and able to interact with the real world.

Secondly, program activities. Mainly refers to the in-depth exploration of a topic, mainly focused on exploration activities, construction activities, role games. For example, in the construction activities, using computers to draw pictures, compose stories, and write messages, the computer can also record the process to provide parents and children with a longitudinal record of cognitive development.

Thirdly, generate a course. In the generation of courses, computer software can be a tool for young children to explore, investigate, create and construct. For example, children in the kindergarten class have a strong interest in the map in the activities of the new Beijing, and put forward some questions about the spatial orientation, scale, etc. So how can the children learn more about the relationship between the map and the real scene? The teacher chooses the educational software of the little explorer. The software intuitively presents the map and the real scene ${ }^{[5]}$. The young child can try to operate in the software to express the position of the object more effectively and accurately, and experience the connection between the physical object and the map. Understand the concept of orientation before and after.

\section{Kindergarten e-education needs attention}

\subsection{Placement of electronic equipment}

It has been a popular practice to set up independent computer rooms or computer rooms in many 
kindergartens in China. At present, there are also new types of electronic devices entering the park, such as the iPad. Basically, these devices have limited configuration per shift and are also kept by teachers. This approach will isolate the computer from the learning and life of the child, and separate the teacher from the guidance. The final result must be that the computer and the course cannot be integrated. Therefore, it is recommended to place the electronic device in the activity room of the child to establish the corner of the e-learning. Making electronic devices and learning become the activity materials in the daily life of early children, making the e-learning corners the same as other activity areas, and becoming the content of free games and activities for young children.

\subsection{The role of teachers in e-education and learning}

Firstly, the teacher's attitude and concept. Teachers may be designers of information technology applications and can be obstacles to information technology.

Secondly, teachers are more passive in the selection of some course software. First, what software to buy does not have a voice. Without evaluating the background and experience of the software, it is difficult to select the software as a standard for children's real reactions and needs.

Thirdly, in the process of children using computers, the teacher believes that children's exposure to information technology is much easier to use than teachers, so there is a superficial way for children to explore themselves, and teachers do not need to be familiar with computer software, or There is no need to help children think about what they have learned in the process of use, to guide and construct, so that the value of e-education will be greatly weakened.

\section{References}

[1] Tao Jin. The influence of the introduction of computer-aided education on China's education. Inner Mongolia Normal University, Vol. 1 (2010) No.50, p. 7-14.

[2] Zhu Sha. Comparative Study on the Development Strategy of Educational Informational in the United States and Singapore. Central China Normal University, Vol.4 (2013) No.25, p. 125-128.

[3] Zhang Wei. Research on Early Childhood Education Software Evaluation Based on Multiple Intelligence Theory. Primary and Secondary School Audio-visual Education, Vol. 12 (2018) No.22, p. 132-134.

[4] Xiao Junwei, Yang Huijie. Study on the Practice of Learning Software Education Based on Children's Attention Stability. Comparative Research on Cultural Innovation, Vol. 2 (2018) No.22, p. 105-107.

[5] Guo Liping, Information Technology and Early Education. Shanghai: East China Normal University Press, Vol. 3 (2007) No.31, p. 17-20. 